\title{
Sustainable urban transportation development in China: A behavioral perspective
}

(C) The Author(s) 2021. This article is published with open access at link.springer.com and journal.hep.com.cn

\begin{abstract}
The rapid development of economics requires highly efficient and environment-friendly urban transportation systems. Such requirement presents challenges in sustainable urban transportation. The analysis and understanding of transportation-related behaviors provide one approach to dealing with complicated transportation activities. In this study, the management of traffic systems is divided into four levels with a structural and systematic perspective. Then, several special cases from the perspective of behavior, including purchasing behaviors toward new energy vehicles, choice behaviors toward green travel, and behavioral reactions toward transportation demand management policies, are investigated. Several management suggestions are proposed for transportation authorities to improve sustainable traffic management.
\end{abstract}

Keywords sustainable urban transportation, transportation behaviors

\section{Introduction}

With the rapid expansion of China's economy, the urban transportation demand and urban residents' total car ownership have increased exponentially, thereby making traffic congestion a part of people's daily life. Therefore, research has focused on improving efficiency, alleviating congestion, and achieving sustainable development for transportation systems. On the basis of socioeconomic activities, transportation and its related systems drive the

Received September 12, 2020; accepted January 5, 2021

Shuai LING, Shoufeng MA, Ning JIA ( $\varangle)$

College of Management and Economics, Tianjin University, Tianjin 300072, China

E-mail: jia_ning@tju.edu.cn

The research is funded by the National Natural Science Foundation of China (Grant Nos. 71431005 and 71701146) and Tianjin Social Science Planning Project (Grant No. TJGL15-026). socioeconomic system. For the sustainable development of transportation systems, it should be optimized with consideration of social-economic-environmental systems (Fig. 1).

On the one hand, transportation systems are aimed at realizing the movement of persons or materials and ensuring the function of socioeconomic systems. China's gross domestic product has increased by $6.1 \%$ from the previous year; the total population was about 1.4 billion, with an increase of 4.67 million in 2019. Meanwhile, the numbers of civil automobiles and passenger automobiles reached 260 million and 220 million, representing increases of $8.83 \%$ and $9.37 \%$, respectively. The number of online ride-hailing users reached 340 million, which marks an increase of $19.3 \%$. Hence, social and economic development inevitably triggers an increase in transportation demand and supply. At the end of 2018, the average density of road networks in 36 major cities across China was $5.96 \mathrm{~km} / \mathrm{km}^{2}$. The investment in transportation in 2019 reached 3245.1 billion yuan, which equates to a $3.1 \%$ increase. Moreover, the total mileage of highways and urban road networks respectively increased by $3.1 \%$ and $3.8 \%$ over the previous year. In sum, urban transportation systems face unprecedented development pressure.

On the other hand, the development of transportation systems is restricted by resources and environment systems. Environmental pollution and energy waste of transportation have become serious problems. In addition to visible black carbon emissions and haze, nitrogen oxide $\left(\mathrm{NO}_{x}\right)$ and carbon dioxide $\left(\mathrm{CO}_{2}\right)$ emissions have rapidly increased. The transport sector trails behind the industrial sector as the second largest source of $\mathrm{CO}_{2}$ emissions. In 2018, the four pollutants emitted by motor vehicles nationwide reached 40.653 million tons, that is, 30.894 million tons of carbon monoxide (CO), 3.688 million tons of hydrocarbons (HCs), 5.629 million tons of $\mathrm{NO}_{x}$, and 442000 tons of particulate matter (PM). The emissions of $\mathrm{CO}, \mathrm{NO}_{x}$, and $\mathrm{PM}$ by automobiles exceed those by motor vehicles by $90 \%$, and they are the main factors that cause air pollution emissions from vehicles. The environmental 


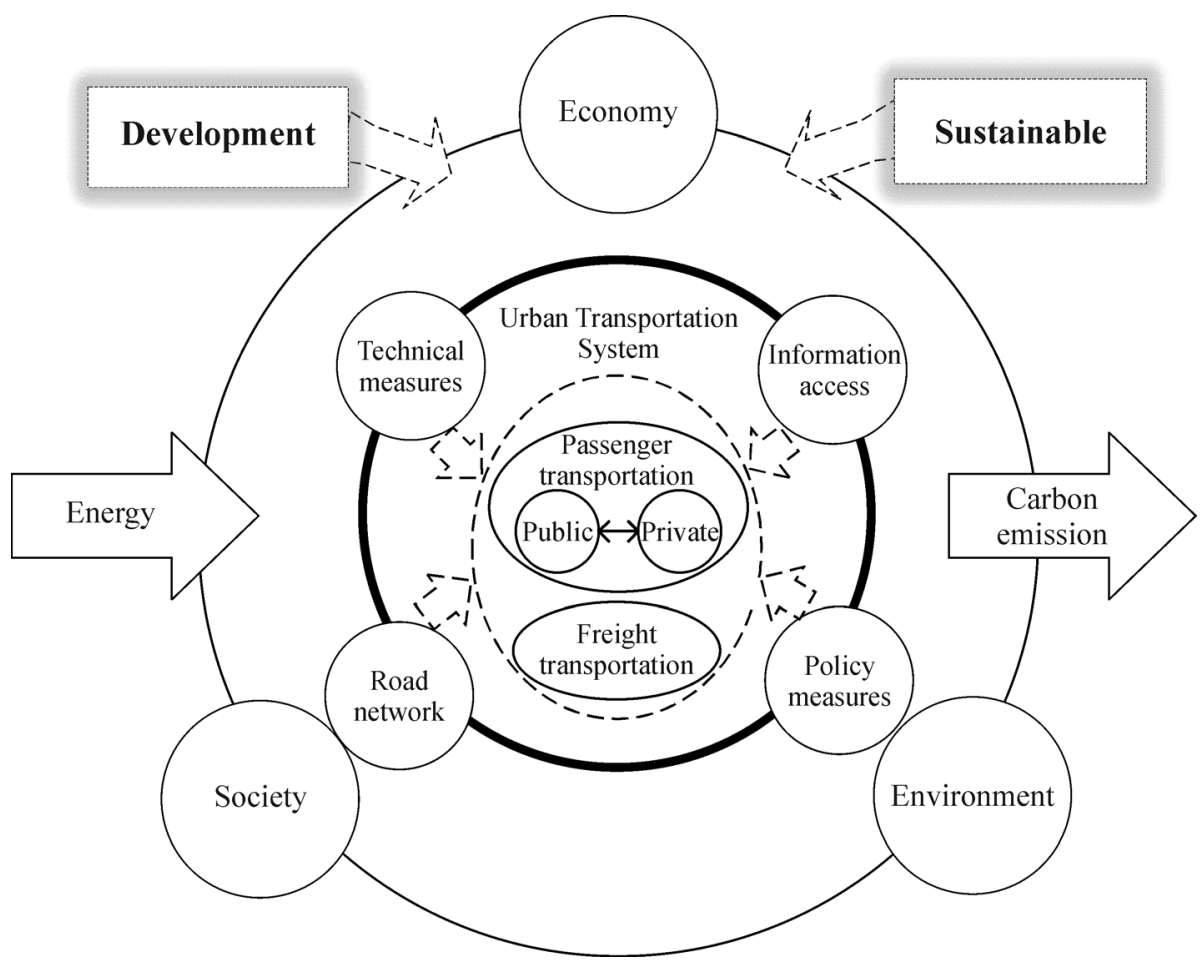

Fig. 1 Relationship and interaction between urban transportation, society, economy, and environment systems.

pressure caused by transportation systems will become unbearable if it emerges along the existing development pathway. Sustainable development has become the universal consensus, and the carrying capacity of the environment must be considered in developing transportation systems. Transportation systems should reduce resource consumption and emissions to meet the needs of environmental systems.

However, the current operation principle, management mode, and capability of transportation systems do not match the dual goals of high efficiency and low emissions. First, the partial conflicts between high efficiency and low carbon emissions hinder the win-win situation between efficiency and green design under current conditions. Second, urban transportation administrators tend to focus on efficiency while neglecting the environment. Moreover, their management processes are mainly based on traditional economic, administrative, signal, and information methods. The measures for cultivating traffic participants' awareness of green travel and low carbon emissions are relatively absent. Third, behaviors and results show deviations. The behaviors of pursuing profits and efficiency dominate transportation systems and deviate from the philosophy of green and sustainable development.

In summary, transportation systems are under great pressure from socioeconomic and environmental systems. The former requires the rapid growth of transportation systems, whereas the latter needs transportation systems that do not exceed environmental capacity. Establishing a balance between these seemingly contradictory requirements is the key to achieving sustainable transportation.

The conflict between the two requirements appears to be a paradox. Hence, the following question arises: What should we do to achieve a sustainable transportation system that can meet the requirements? This question motivates our research. Our solution is rooted in the origin of all complex transportation activities, that is, individual behaviors. We argue that we should analyze and understand transportation-related behaviors, on the basis of what efficient policies could be designed. The remainder of this paper consists of five parts. Section 2 presents the research framework. Sections 3, 4, and 5 present our analysis of different transportation-related behaviors, including purchasing behaviors toward new energy vehicles (NEVs), choice behaviors toward green travel mode, and behavioral reactions toward transportation demand management (TDM) policies. These sections provide important basis for policy design. Section 6 provides the research conclusions.

\section{Research framework}

\subsection{Levels of transportation management}

We believe that only with appropriate management and regulation of urban transportation systems can the possible sustainability of urban transportation development be discussed. Therefore, we analyze transportation systems 
structurally and systematically. The management of transportation systems can be divided into four levels from the macro to micro perspectives (Fig. 2).

The arrows in Fig. 2 represent the transitivity of transportation system management. The closer the regulatory methods are to the upper layer, the greater the influence is, but the slower such influence comes into force; the closer those methods are to the lower layer, the smaller the influence is, but the faster such influence comes into force. Higher-level regulatory methods are macroscopic and general, whereas lower-level methods are microscopic and specific.

1) The balance between transportation demand and supply is the most important factor at the first level. On the one hand, discussions on efficient and green transportation will be useless if the supply cannot meet the demand. On the other hand, transportation supply cannot meet transportation demand passively; otherwise, demand would expand disorderly. Regulatory policies should instead be adopted to guide transportation demand. Transportation supply is mainly determined by transportation infrastructure, such as road utilities, whereas transportation demand and its spatial-temporal distribution characteristics and the characteristics of traffic distance are affected by urban patterns and land use types. Reasonable urban forms and land use patterns can help reduce the total demand and lead to changes in demand characteristics.

2) The second level is the structural adjustment of transportation, i.e., the proportion of different transport modes. Under identical transportation capacity, the occupied road resources and exhaust emissions by public transportation are far less than those by private transportation (Table 1).

Under a fixed transportation demand, increasing public
Table 1 Per capita spatial and temporal consumption of different transportation modes

\begin{tabular}{lcccc}
\hline Transportation modes & Bicycle & Walking & Bus & Vehicle \\
\hline Speed $(\mathrm{km} / \mathrm{h})$ & 12 & 4 & 15 & 20 \\
Horizontal width $(\mathrm{m})$ & 1 & 0.6 & 3.75 & 3.75 \\
Vertical spacing $(\mathrm{m})$ & 3.44 & 1.46 & 16.35 & 11.13 \\
Passenger capacity & 1 & 1 & 50 & 1.2 \\
Per capita spatial and temporal & 2.95 & 2.25 & 0.73 & 15.58 \\
$\begin{array}{l}\text { consumption index } \\
\left(\mathrm{m}^{2} \mathrm{~h} / \text { vehicle/person) }\right.\end{array}$ & & & & \\
\hline
\end{tabular}

transport and its share rate, decreasing the number of motor vehicles, and promoting slow traffic in short-distance travel can greatly reduce the total exhaust emissions. As the potential of increasing supply is relatively limited in many large cities, the adjustment of the transportation structure is the most effective way to achieve green transportation.

3) The optimization of road network structures and scientific transportation regulatory methods (advanced regulatory methods, such as traffic control and traffic guidance) are the last two levels. This task contributes to the realization of smooth and orderly transportation, while the reduction of undesirable traffic states (such as idle speed, low speed, and stop-and-go) will effectively limit vehicle emissions. These methods can only improve traffic conditions under the given transportation supply and demand and thus have relatively limited contributions to green transportation. Nevertheless, they are advantageous because of their low cost and immediate impact.

The regulatory level of transportation systems is the important foundation for the shift of transportation

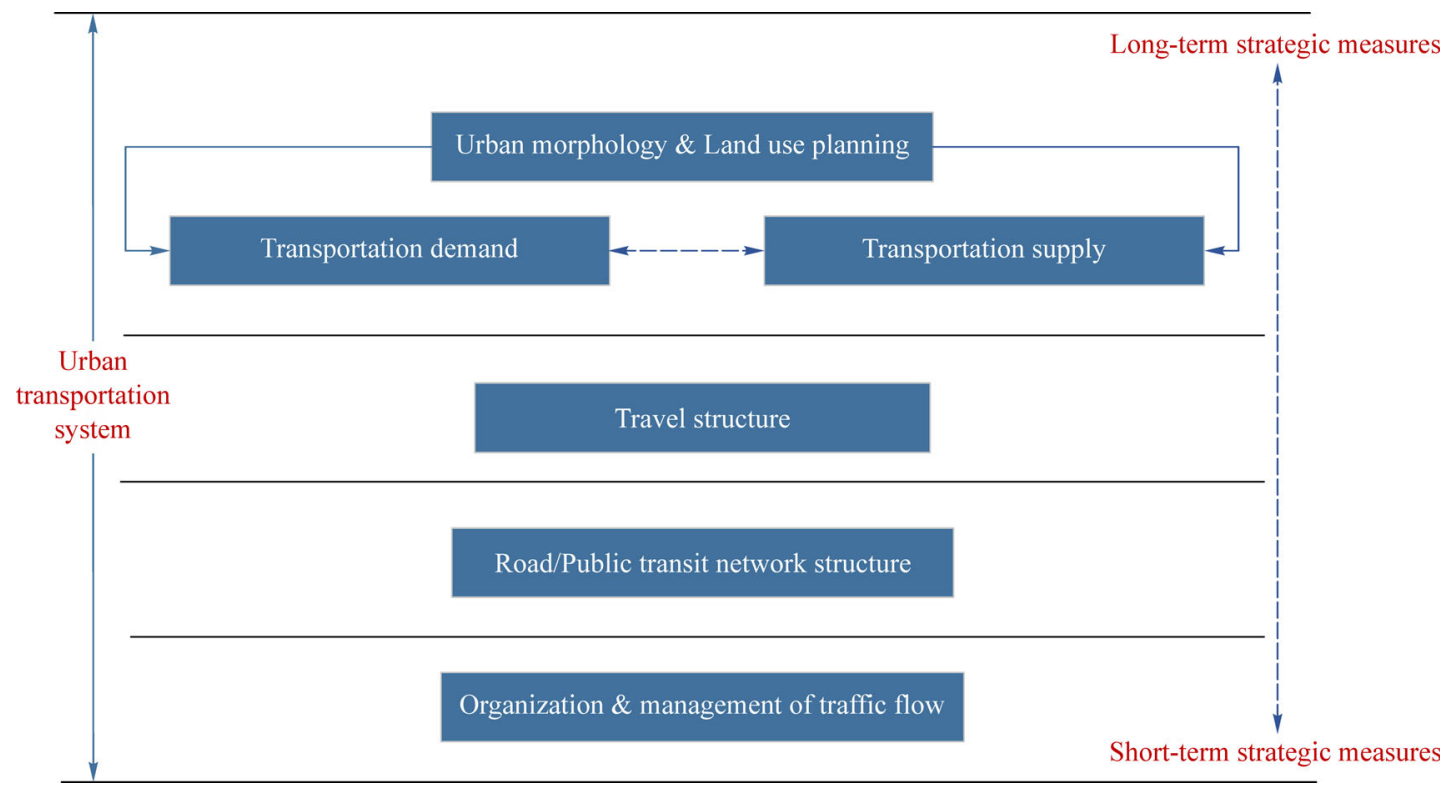

Fig. 2 Levels of transportation systems. 
development modes and the realization of green transportation. According to the stages of urban development, urban form, urban economic level, and population structure, transportation administrators should choose several levels as the starting point and propose policies to achieve goals. For example, in many big cities, the road supply becomes saturated and is thus challenging to increase. Therefore, transportation management and structure should be adjusted to realize the green and healthy development of transportation. Meanwhile, in some small cities, the philosophy of green transportation should be introduced at the initial phase of planning.

These regulatory levels present unipolarity from top to bottom. The upper level methods exert strong influence on the lower level methods while the lower level methods have weak reaction to the upper level methods, i.e., lower level methods are difficult to apply to upper level issues. Thus, upper level methods are the fundamental and effective ways to develop green transportation.

From a management perspective, these regulatory levels are feasible means to promote the development of transportation in a green and efficient direction.

\subsection{Complex emergence of urban road transportation systems}

The complexity of transportation management stems from its complex emerging characteristics:

- The number of participants is extremely large;

- Participants are subjects with their own purposes and initiatives;

- Participants communicate with the environment and other elements and learn or accumulate experience during the process;

- Participants change their own structures and behavioral patterns according to their learned experience, and the changes drive the evolution of the system.

Transportation systems belong to complex adaptive systems, which have high autonomy and involve the adaptive behavior of individuals. Thus, simply optimizing or controlling relevant measures is not enough to guide individuals in achieving the goals of policy makers.

The management of complex transportation systems is a typical issue in the organization and coordination of individual behaviors and activities. The process essentially involves regulating individual behaviors and achieving the overall goals of social-economic-environment systems. At the micro level, contradictions cause individual losses during low carbonization in the transport sector. Therefore, traditional physical methods face the risk of failure or unacceptance of participants.

Therefore, a change in consciousness is the key to achieving personal green transportation. Researchers have pointed out that changing individual consciousness is the key to realizing sustainable transportation (Jiang et al., 2013; Wang et al., 2020; Yang et al., 2020; Zhang and Tu,
2021). Mandatory measures have limited effects. Therefore, policy makers should focus on guidance rather than suppression (Dacko and Spalteholz, 2014; Ling et al., 2019; Du et al., 2020; Xu et al., 2020).

\subsection{Behavior-based management for sustainable urban transportation}

On the basis of the previous analysis, we contend that the pathway to achieve the sustainable development of urban transportation involves a focus on the optimization and adjustment of the transportation structure. Designing a complete policy system, changing participants' consciousness and behaviors, restricting private transport, and increasing public transport are necessary to realize green, efficient, and sustainable transportation systems. Moreover, participants' consciousness and behaviors are in the dominant position, and they determine whether a policy can achieve the expected objectives. Therefore, the sustainable development policy of urban transportation is analyzed herein from the behavior perspective. According to Fig. 2, the discussions are conducted from the following three perspectives:

- Purchasing behaviors toward NEVs;

- Choice behaviors toward green travel mode;

- Behavioral reactions toward TDM policies.

\section{Purchasing behaviors toward NEVs}

The increase in private car ownership has brought numerous challenges to urban transportation and environmental protection. Under such circumstances, the advent and popularization of NEVs present new opportunities to mitigate traffic pollution while reducing energy consumption. Therefore, consumers' purchasing and adoption intention toward NEVs should be studied. In addition, correctly understanding the obstacles in the large-scale implementation of NEVs in the current social environment and overcoming them can improve the market sharing of NEVs. Furthermore, proper measures and policies to encourage consumers to choose NEVs instead of internal combustion engine vehicles (ICEVs) are of great significance to environmental protection and urban transportation development.

\subsection{NEV incentive policies in China}

In the face of the increasing severity of urban traffic pressure, air pollution, and energy consumption, eight cities (Beijing, Guangzhou, Hangzhou, Nanjing, Shanghai, Shenzhen, Tianjin, and Xi'an) and Hainan Province in China, have carried out various incentive policies to encourage people to use NEVs. By 2018, nearly 20 cities in China had introduced incentive policies for NEV use. For example, NEVs in Tianjin are not be subject to tail 
number restrictions, and Hainan Province has proposed a policy requiring all newly purchased government vehicles to be NEVs. In some cities, people who buy NEVs can obtain free license plates, purchase subsidies, or tax relief. To meet the increasing charging requirements of NEVs, local governments have constructed many charging facilities and parking lots. These policies are proposed to alleviate environmental pollution and energy consumption by promoting the use of NEVs. The detailed rules for NEV incentive policies in China are shown in Table 2.

\subsection{Current research}

The Chinese government not only limits the increase of motor vehicles through restriction policies but also encourages the purchase and use of NEVs. Similar policies are in place in other countries. Take Norway for example. The market share of battery electric vehicles (BEVs) in the country is among the highest in the world. To study the role of incentives and identify which incentives exert an important impact on the purchase of BEVs, Bjerkan et al. (2016) conducted a survey of 3400 BEV owners in Norway and found that purchase price and VAT (valueadded tax) are important incentives for BEV adoption for more than $80 \%$ of the subjects and that early price reduction is the most critical incentive. Diamond (2009) explored the influence of incentive policies on BEVs in America via cross-sectional analysis. The results suggested that incentive policies exert a slight influence on hybrid adoption. Other subjective and objective factors can also influence car purchasing behavior, including consumers' psychology and BEVs' functional and infrastructural factors (Coffman et al., 2016; Cohen et al., 2016; Mersky et al., 2016). From the perspective of consumers, Lane and
Potter (2007) and Coffman et al. (2016) examined factors such as cost, performance, reliability, low carbon consciousness, capability, and purchase price. Carley et al. (2013) found that driving range, recharging time, and upfront cost have a great influence on consumers' intention to purchase. Furthermore, consumers with strong environmental consciousness show great interest in BEVs (Krupa et al., 2014; Rezvani et al., 2015; Bonges III and Lusk, 2016; Biresselioglu et al., 2018).

\subsection{Barriers to extensive adoption of BEVs}

Under the pressure of environmental pollution and energy consumption, the municipal government of Tianjin has vigorously promoted the wide application of BEVs. Although a series of policies, including purchase subsidies and tax relief, has been implemented and BEV users can obtain licenses through a lottery different from that for ICEVs, the BEV market only accounts for $1.34 \%$ of 24.59 million private cars. In the widespread adoption of BEVs, some obstacles play important roles. She et al. (2017) recently conducted a study on BEV adoption barriers, i.e., financial barriers, vehicle performance barriers, and infrastructure barriers from the consumer perspective.

A total of 476 online and offline questionnaires were obtained in Tianjin to investigate consumers' opinions on $\mathrm{BEV}$ adoption and its related barriers. The questionnaire contained four parts, namely, demographic information, attitudes toward incentive policies, public acceptance of BEVs, and barriers of BEV adoption. After collecting the samples, they applied structural equation modeling (SEM) and maximum likelihood estimation to analyze the relationship between latent barriers and BEV acceptance. Furthermore, they conducted a chi-square test on the null

Table 2 NEV incentive policies in China

\begin{tabular}{lcc}
\hline City/Province & Policies encouraging to purchase & Policies encouraging to use \\
\hline Beijing & Subsidy for purchasing (2013.11) & No driving restrictions (2017.12) \\
Guangzhou & Setting license plate without lottery and auction (2013.11) & No driving restrictions (2019.08) \\
Hainan Province & Getting license plate without lottery and auction (2012.06) & No driving restrictions (2019.03) \\
Gangzhou & Getting license plate by number (2018.08) & No driving restrictions (2021.05) \\
Nanjing & Subsidy for purchasing (2020.04) & No driving restrictions (2017.03) \\
Shanghai & Subsidy for purchasing (2014.03) & Allowed to drive in the bus lane (2017.03) \\
Shenzhen & Getting license plate without lottery and auction (2017.03) & No driving restrictions (2020.10) \\
& Getting license plate for free (2016.01) & No driving restrictions (2019.01) \\
Tianjin & Subsidy for purchasing (2016.01) & No driving restrictions (2013.12) \\
Xi'an & Subsidy for purchasing (2014.03) & Getting license plate by lottery (2014.03) \\
& Subsidy for purchasing (2013.12) & No driving restrictions (2014.10) \\
\hline
\end{tabular}


hypothesis to explore the statistical correlation between variables.

The results showed that consumers believe in the potential of BEVs but their interest is not high at present. First, safety, reliability, and mileage are among the top concerns, and they indicate that vehicle performance is significant in the impediment of BEV adoption. Therefore, government and vehicle manufacturers should concentrate on the performance of BEVs, which is an effective way to enhance consumer confidence. Second, high battery cost exerts a negative effect on BEV adoption. In addition to the initial purchase cost, BEVs' total cost also includes battery and maintenance costs. Thus, incentive policies should include new battery and maintenance subsides. Third, the lack of charging infrastructure is the most serious barrier among various infrastructure barriers. For the convenience of consumers, policy makers should pay close attention to the quantity, location, and distribution of charging infrastructure. Finally, older consumers hold a positive attitude toward adopting BEVs, and consumers with more family members tend to purchase BEVs as their second private cars.

\subsection{Influence of social-psychological predictors on NEV} purchase intention

$\mathrm{Du}$ et al. (2018) pointed out that social-psychological factors influence consumers' purchasing intention and behaviors, which have not been considered by policy makers in China. This section provides a series of psychosocial factors based on the theory of planned behavior (TPB), including attitudes toward NEVs, subjective norms, perceived behavioral control, personal norms, and government policies. For the low carbon awareness behavior gap between motivations and behaviors, its formation and its relation to low carbon awareness are not broadly studied in the literature. In this section, the moderator variables, including low carbon value, low carbon subjective knowledge, and low carbon objective knowledge, are used to investigate the impact of low carbon awareness on the intention to purchase NEVs.

The present study acquires the original data from 811 valid survey questionnaires in Tianjin, which included three parts: Public social-psychological perception toward NEVs, 10 items to measure low carbon awareness, and demographic information. In the data analysis, Pearson's correlation coefficient and hierarchical regression are employed to establish the relationship between various variables about NEV purchase intention.

Five important implications are identified. First, attitude, subjective norms, perceived behavioral control, and personal norms exert significant effect on the intention to purchase NEVs. More important, subjective norms have the strongest effects on purchase intention, that is, people are willing to purchase NEVs when they are advised by other people or they know that their family members, colleagues, or friends own one. Potential consumers' selfperception and psychology influence their decisions on NEV adoption, and the government should encourage them to enhance the awareness of the concept of green consumption and guide them in playing a leading role in promoting low carbon transportation infrastructure. Second, government policies are significantly related to NEV purchase intention. Incentive policies are important, which include lowering the costs for the driving and maintenance of NEVs, improving public facilities, NEV technology, and infrastructure, and reducing the cost of NEVs. Third, low carbon value exerts a slight moderating effect on NEV purchase intention, thereby reflecting a gap between awareness and behavior. Fourth, low carbon subjective knowledge exerts a significant moderating effect on behavior through attitudes and subjective norms. On the one hand, people who have high level of environmental knowledge would have a positive attitude toward NEVs. On the other hand, these people can make reasonable decisions and choose not to purchase NEVs rather than be influenced by herd mentality. Therefore, the government should boost consumers' low carbon awareness so as to enhance their rational understanding of NEVs. Finally, low carbon objective knowledge exerts a negative effect on the relationship between perceived behavioral control and NEV purchase intention.

\section{Choice behaviors toward green travel mode}

As an effective measure of solving the urban traffic contradiction and reducing carbon emissions, green travel mode has become increasingly popular among managers and travelers. A large number of countries have incorporated green travel into key research issues related to transportation development, and they have made various efforts and attempts. Academia generally pays close attention to the choice behaviors toward green travel mode. Most studies have focused on the analysis of factors affecting travelers' low carbon transportation willingness and behaviors. In this section, China's policies that promote green travel mode and the related research into low carbon transportation are introduced.

\subsection{Policies promoting green travel mode in China}

As an important way to solve the contradiction between urban transportation demand and supply and environmental problems, China has raised the low carbon and public transportation to the national strategic level since the beginning of this century. The central government and local government units have issued a series of policy documents to accelerate the priority development of public transportation. Low carbon and public transportation has gradually received attention from all sectors of society. 
Thus far, many priority development strategies for urban public transport have been implemented for nearly 20 years. Under the guidance of policy, technology, and theory, public transportation is also at an important development stage.

In China, the concepts of "low carbon commuting", "giving priority to the development of public transportation", and "public transport city" have long been proposed. In June 1997, the first bus lane in China was opened in Chang'an Street, Beijing. Thereafter, the technology of public transport greatly improved. In 2004, the Ministry of Construction emphasized the prioritization of the development of urban public transportation and suggested that the guiding role of urban planning should be strengthened, the facilities of urban public transportation stations should be improved, public transportation road systems should be constructed, and relevant economic policies for prioritizing the development of urban public transportation should be formulated to improve overall technology level and industry service quality ${ }^{1)}$. During the 12th Five-Year Plan period, the Ministry of Transport organized two batches of "transit metropolis" construction demonstration projects; implemented the priority development strategy of urban public transport; proposed to improve the support policies of urban public transport in terms of planning, land, capital, finance and taxation, right of way, technology, and other aspects in the government-led process; and increased the subsidy funds for the establishment of the transit metropolises. In 2010, Shenzhen was acknowledged as the first "transit metropolis" demonstration city in China. In the same year, the Ministry of Transport issued the Regulations on Public Transport, which guarantees the prioritization of public transport in law. At the end of 2012, the State Council issued guiding opinions on the priority development of public transportation in cities, which emerged as a national strategy ${ }^{2}$. The document specifies that the priority development of public transportation is to increase transport capacity, improve service level, enhance the competitiveness and attraction of public transportation, etc. Through some specific methods, such as the use of large-capacity public transportation, the construction of a comprehensive transfer hub, and the improvement of station coverage rate, the share rate of public transport is improved, and public transportation plays a leading role in motorized travel. By the end of 2015, the public transportation priority development policy system for the two batches of 37 innovative pilot cities in China was further improved and implemented ${ }^{3)}$. In 2019, the Ministry of Transport issued a notice on the issuance of the Digital Transport Development Plan, which clearly promoted the development of "Internet +" convenient transportation, and encouraged and standardized the development of low carbon, public transportation services, such as customized buses, intelligent parking, intelligent public transportation, and so on ${ }^{4)}$.

\subsection{Current research}

In addition to the government's preference for low carbon transportation, researcher support is also placed on it. Researchers have shown that low carbon and public transportation has unique advantages and can maintain the positive and healthy development of urban transportation. They have focused their research on exploring the factors that influence people's low carbon travel intentions and behaviors.

Many relevant theoretical frameworks have been introduced to determine the factors affecting people's intention toward low carbon travel and explain the mechanism of these factors (Dittmar, 1992; Gärling et al., 2003; Donald et al., 2014; Lind et al., 2015). Such frameworks focus on people's psychological state or their car usage behavior and combine internal factors (i.e., psychological) and external factors (i.e., traffic policy impact) (Marsden and Docherty, 2013; Marsden et al., 2014; Hafner et al., 2017). Take the following two theories as examples. The TPB predicts that positive attitudes, strong subjective norms, and perceived behavior control will promote individuals' general willingness to perform environmentally friendly behaviors (Kaiser and Scheuthle, 2003; Steg and Vlek, 2009). As for the theory of value belief norm (VBN), different types of environmental behavior are considered to be the result of personal norms, attribution of responsibility, and awareness of consequences (de Groot and Steg, 2010). Personal norms are defined as the degree to which individuals perceive living in an environmentally friendly way as a responsibility. Responsibility attribution refers to the decision taken by an individual after considering the wide-ranging consequences of the decision. Consequence awareness generally refers to the situation in which an individual realizes that his decision will negatively affect himself or the external environment; this individual's decision will inevitably be affected (Liu et al., 2017). These factors have also been used in the study of energy consumption behavior (Steg and Gifford, 2005; Botetzagias et al., 2015) and private car usage behavior (Gärling et al., 2003; Liobikienè et al., 2016). Other research has also extended the models of the TPB and VBN theory by introducing descriptive norms, perceived environmental concerns, perceived moral obligations, green trust and habits, and other variables (Cristea et al., 2013; Chen et al., 2014; Donald et al., 2014; Choi et al., 2015; Lo et al., 2016).

As a result of the emergence of many low carbon trip

1) Available at: gov.cn/gongbao/content/2005/content_92902.htm

2) Available at: gov.cn/zwgk/2013-01/05/content $230 \overline{4} 962 . \mathrm{htm}$

3) Available at: bus-info.cn/?c $=$ article\&id $=148 \overline{8}$

4) Available at: gov.cn/xinwen/2019-07/28/content_5415971.htm 
modes, the choice of transportation mode has become an important part of low carbon travel behavior analysis. Some efforts have been made to find the factors influencing the choice of commuting methods. For example, material possession theory (MPT) provides three components, i.e., symbolic factors, affective factors, and instrumental factors, all of which have been proven to exert an important influence on people's choice of commuting methods (Steg et al., 2001; Lois and López-Sáez, 2009; Bergstad et al., 2011; Van et al., 2014). The symbolic factor refers to the degree of an individual's awareness of his/her social or personal identity when he/she chooses a commuting mode. The affective factor refers to how people feel about each mode of commuting. The instrumental factor refers to the functionality and usefulness of commuting patterns perceived by individuals. Apart from the factors in MPT, the factors related to low carbon also exert a vital impact on the choice of commuting patterns (Gadenne et al. 2011; Martinsson et al. 2011). Some studies have shown that when residents have a good attitude toward the environment, they are likely to engage in energy conservation (Clarka et al., 2003; Gadenne et al., 2011; Martinsson et al., 2011). Such engagement can effectively enable them to take environmentally-friendly travel behaviors to improve the environmental attitudes and awareness of residents (Noppers et al., 2014; 2015). In the effort to improve the above-mentioned factors related to low carbon, three main aspects, i.e., low carbon awareness, low carbon knowledge, and low carbon habits, have been proposed (Jia et al., 2018). Low carbon awareness mainly relates to commuters' ecological world view. It can generally be regarded as a determinant of behavior intention and behavior. Low carbon knowledge represents carbon emission knowledge from different sources. Low carbon habits is a derivative of the first two factors, and it refers to the habits aimed at reducing an individual's overall carbon footprint.

\subsection{Adoption of green travel mode}

This study is based on two related research articles, which narrow the research limitations of the influencing factors of intentions and behaviors toward low carbon and public travel. The first research studied the relationship among travelers' low carbon travel intentions, social-psychological variables, and government policies (Liu et al., 2017). Carbon emission is one of the biggest reasons for global warming, and this problem is threatening humans' wellbeing (Hu et al., 2015; 2016). Low carbon travel, one of the most effective ways to suppress this problem, has attracted much attention. Previous research on people's low carbon travel intention is often based on a single theoretical perspective, and the results cannot effectively explain people's behavior intention. Meanwhile, Liu et al. (2017)'s research combined the TPB and VBN theory to improve the interpretation ability of this intention modeling. The research hypothesized that the factors from the TPB and VBN theory directly affect residents' low carbon travel intention. Furthermore, low carbon awareness and low carbon travel policy exert an indirect effect on the intention. The theoretical model is shown in Fig. 3.

To test the conclusions empirically, we conducted a

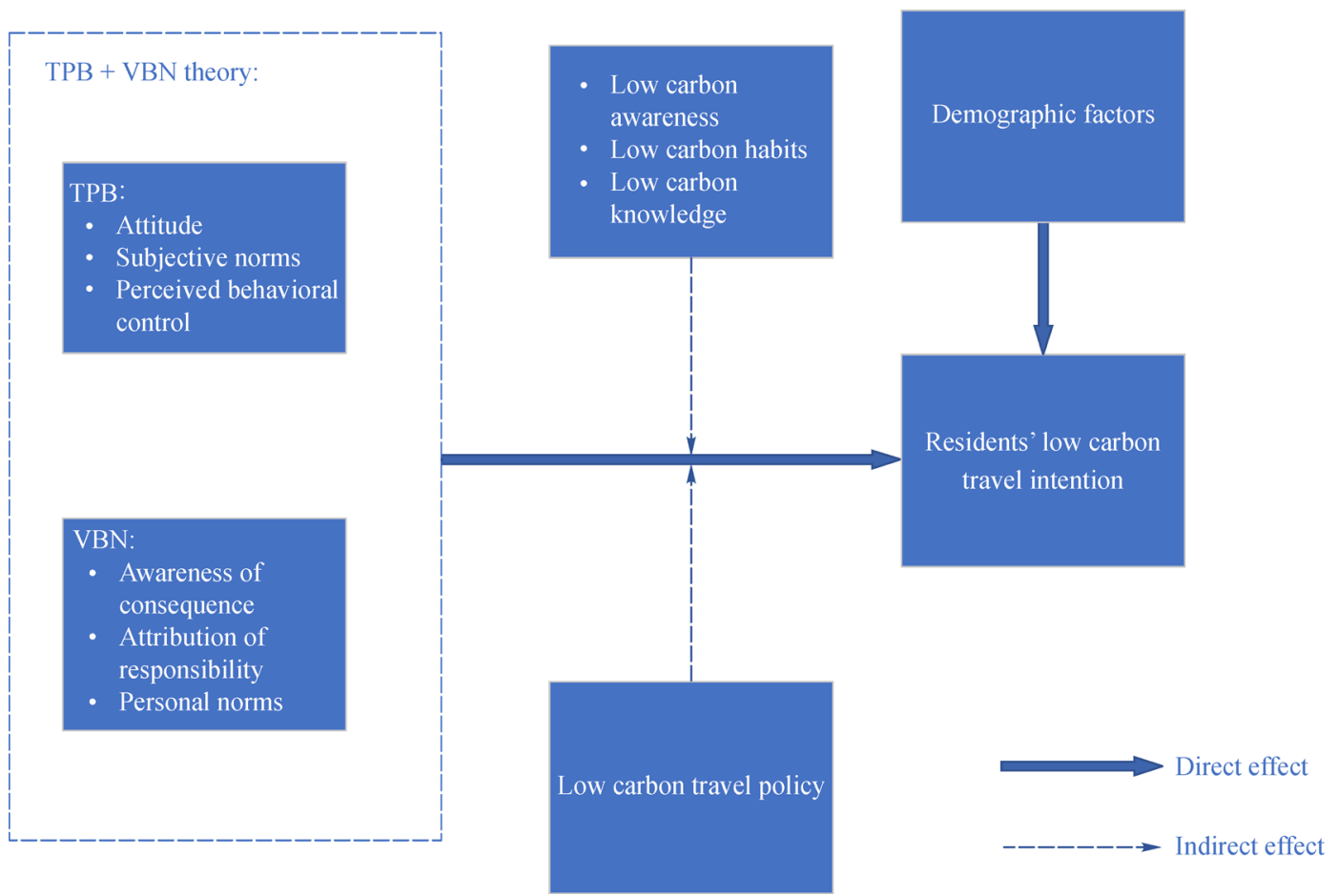

Fig. 3 Theoretical framework for selecting a low carbon travel mode based on the TPB and VBN model (according to Liu et al., 2017). 
survey in Tianjin, one of the four municipalities directly controlled by the Chinese central government. In this study, SEM was applied to analyze the survey data of 811 residents, and several conclusions were obtained. As shown in Fig. 4, attitudes, subjective norms, perceived behavior control, awareness of consequences, responsibility attribution, and personal norms exert a positive impact on residents' willingness toward low carbon travel. Analysis shows that personal norms have greater direct influence on low carbon travel intention than perceived behavioral control or attitudes. Meanwhile, through subjective norms, low carbon awareness exerts a great indirect influence on trip intention, which is in accordance with previous findings. Figure 4 shows that transportation policy has an indirect positive and obvious influence on low carbon travel intention through the awareness of consequences, attribution of responsibility, personal norms, attitudes, and subjective norms. In general, VBN variables are better than TPB variables in terms of explaining residents' choice of low carbon travel mode. Personal norms have the greatest impact on travel willingness. Such self-responsibility will enhance the potential of low carbon travel for residents. Personal norms, as an important variable, affect TPB variables through perceived behavior control. Conversely, low carbon awareness exerts an insignificant indirect impact on residents' low carbon travel willingness, which cannot be transformed into low carbon behavior.
As for the other study, Jia et al. (2018) combined widely used attitude factors with low carbon awareness, low carbon knowledge, and low carbon habits and then studied the relationship between these factors and commuters' choice behavior. Policy changes alone cannot guarantee long-term improvements in transport conditions and reduction of carbon emissions. Hence, the behavioral factors determining commuters' choice of travel patterns should be investigated. On the basis of previous studies, the current work proposes a conceptual model of commuting choice, which combines MPT variables with low carbon-related factors (low carbon knowledge, low carbon awareness, and low carbon habits), behavioral intention, and actual behavior (Fig. 5). Behavioral intention is the dependent variable. In this study, a crosscity survey was conducted in three cities in China (Beijing, Jinan, and Hangzhou) so as to prove that low carbonrelated factors are indeed important for the choice of commuting patterns.

The questionnaires were distributed across Beijing, Hangzhou, and Jinan to verify the theoretical model. Through a series of data analyses (i.e., binary logistic regression analysis, combined analysis, and cross-city analysis of traffic policy impact), the following results are obtained. First, low carbon knowledge and low carbon habits directly affect the choice of commuting modes. Moreover, low carbon knowledge and internal factors are the two strongest predictors for the choice of commuting

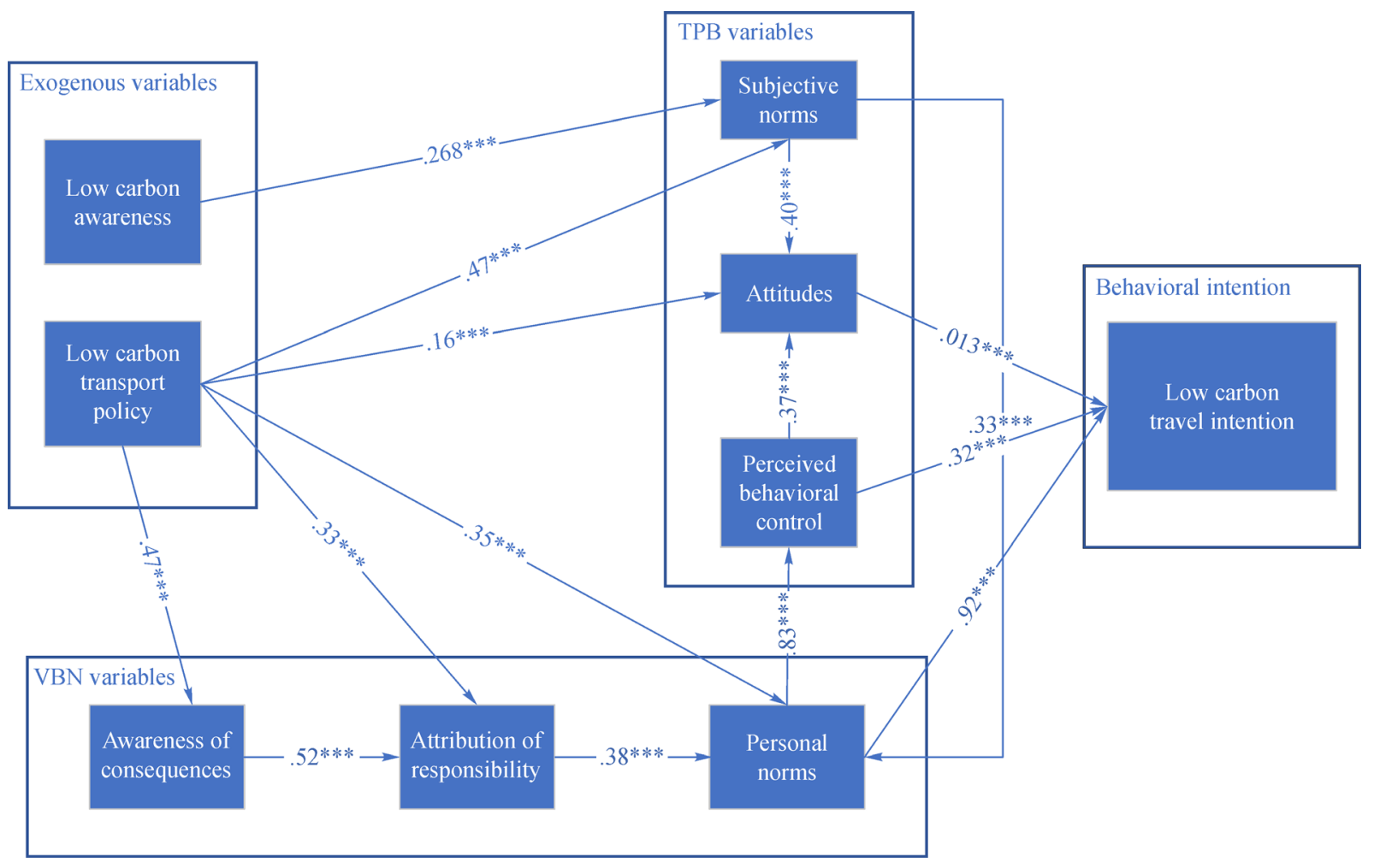

Fig. 4 Results of structural equation modeling (according to Liu et al., 2017). 


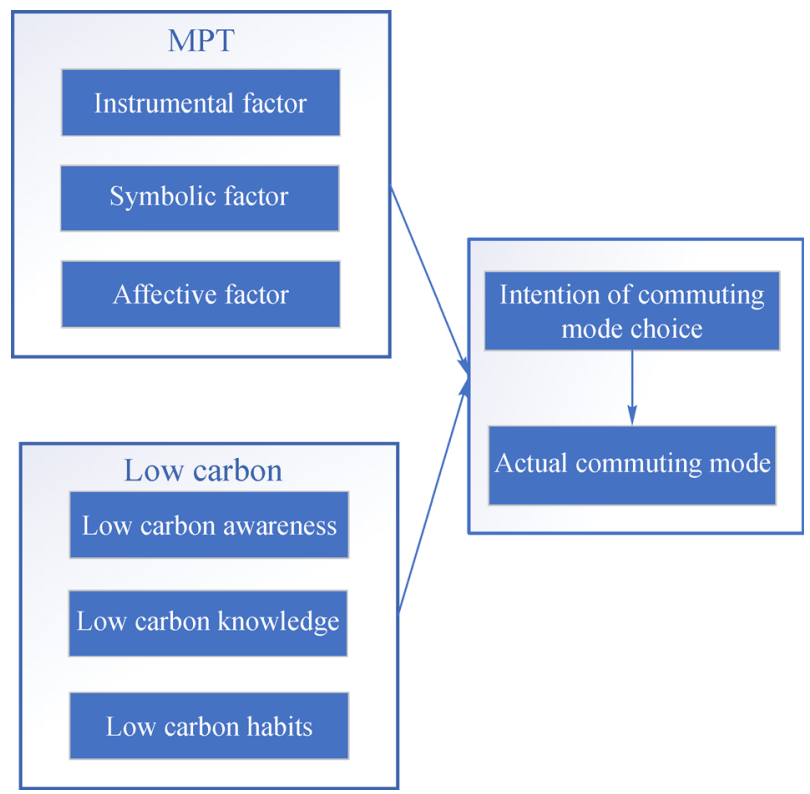

Fig. 5 Theoretical framework for selecting low carbon travel patterns based on the MPT model (according to Jia et al., 2018).

modes. Second, a large gap exists between behavioral intention and actual choice. Finally, the survey found significant differences among the three cities. Relevant explanations are given accordingly in Jia et al. (2018). These findings offer some enlightening effects on policymaking for the design and promotion of the use of public transport.

\section{Behavioral reactions toward TDM policies}

The rapid increase in private car ownership and usage in today's society has made residents' lives inconvenient. Originating in the 1970s, TDM is a recommended method for dealing with such inconvenience. Traditional TDM strategies include carpooling, public transport system, road pricing, and license plate restriction (LPR). These strategies aim to reduce the choice of private cars for travelers and encourage them to choose non-motorized vehicles (Jraiw, 1991). The most prominent one among these strategies is the LPR policy. In this section, China's LPR policy is first introduced. Through the combination of relevant research on TDM policies and commuters' reactions and attitudes toward them, the behavior reaction mechanism hidden behind the policies is analyzed in depth.

\subsection{LPR policies in China}

In 2008, China implemented the odd-and-even (OAE) policy during the Beijing Olympic Games, in which a partial number of private vehicles were prohibited to drive on the road according to the last number of their license plate. The implementation marked the first time that China implemented the LPR policy. In China, license plate lotteries/auction policies have been implemented in cities such as Beijing, Shanghai, Guangzhou, and Chengdu.

In the current research on LPR policy, a large number of articles have explored the environmental benefits (Chowdhury et al., 2017), safety efficacies (Chowdhury et al., 2017), and improvement of traffic situation (Liu et al., 2017). Most of these studies have concluded that LPR policies can significantly alleviate traffic congestion. However, with the increasing popularity of the LPR policy, some questions arise: What impact will the acceptance of the LPR policy have on the commuting behavior of private car owners? At present, many articles have proposed that the key factors influencing postacceptance are crucial for the acceptance of the LPR policy (Rienstra et al., 1999). The reason is that the acceptance of the LPR policy by travelers is crucial for authorities, who can understand the feasibility of the implementation of the policy through the acceptance of the LPR policy by travelers and further improve the policy (Gärling et al., 2008). From this perspective, we can see that the necessity of studying the tourists' acceptance of the LPR policy.

\subsection{Current research}

Studies have found that the implementation of the LPR policy leads residents to buy more secondhand cars, which will further deepen traffic congestion (Eskeland and Feyzioglu, 1997). Some study has pointed out that travelers are accustomed to private cars and may thus choose to buy more vehicles after the LPR policy is implemented (Goddard, 1997). Some study has used the data from Tianjin to conduct an empirical study on the LPR policy on the basis of the multivariate regression method. The results show that the lower the acceptance level is, the more negative emotions the travelers have toward the policy; and the lower the policy effectiveness is, the higher the acceptance level will be (Jia et al., 2018).

Some studies also explored the related issues from the perspective of traffic violations. Travelers tend to have a negative attitude toward the LPR policy, and at this point, they have low obedience to the policy (Geng et al., 2018). Wang et al. (2014) conducted a survey on individual trips in Beijing, analyzed the data, and found that $47.8 \%$ of the trips violated the LPR policy.

With regard to the effect evaluation of the LPR policy, some studies have explored from a long-term perspective, while others have indicated that when the LPR policy is implemented, traffic congestion becomes effectively improved in a short period (Gallego et al., 2013). A number of studies have also investigated the impact of the implementation of the LPR policy on solving air pollution and alleviating traffic congestion from a long-term perspective; however, the results show that the long-term effect is not ideal (Cantillo et al., 2010). 
Several studies have analyzed relevant issues from the perspective of effectiveness. Viard and $\mathrm{Fu}$ (2015) analyzed the license plate inspection data of Beijing and found that the LPR policy achieves the effect of effective governance. A study analyzed India's OAE day and found that $20 \%$ of the vehicles on India's OAE day did not follow the LPR policy, thereby reducing the effectiveness of the LPR policy (Mohan et al., 2017). Research has also suggested that the additional traffic demand by tourists will also reduce the efficacy of the policy (Jia et al., 2017).

Some studies have analyzed the specific effects of the implementation of the LPR policy. The OAE day effectively restricted $35 \%$ of private car travel after the implementation of the LPR policy in India (Mohan et al., 2017). Li and Guo (2016) analyzed the data of OAE day in Beijing, China, in 2008 and concluded that during the OAE scheme, the traffic volume was only $60 \%-80 \%$ of the original, and the overall driving speed was $110 \%-120 \%$ of the original.

\subsection{Commuters' behavior reactions toward LPR policy}

Jia et al. (2017) recently conducted a study and explored the long-term effects of the LPR policy from a behavioral perspective. In the study, the factors affecting the acceptability and behavior toward the LPR policy were investigated through a survey of commuters in Tianjin, China. Regression analysis was performed to analyze the data, and several interesting results were found. Suggestions were made based on the conclusions for the transportation department to improve commuters' accep- tance of the LPR policy.

The current study proposed a theoretical framework for studying acceptability and behavior reactions toward the LPR policy on the basis of the work of Schade and Schlag (2000). The framework is mainly composed of three parts, as shown in Fig. 6.

About eight months after the implementation of the LPR policy in Tianjin, a questionnaire survey was conducted in November 2014. A total of 1000 questionnaires were sent out, and 704 of them provided valid answers. The research conclusion herein was obtained after analyzing the recovered data.

From a descriptive point of view, the survey results showed that the proportion of Tianjin respondents with strong and moderate support for the LPR policy is about $70 \%$. In other words, a large number of respondents tended to support Tianjin's LPR policy. During the restricted working days, the proportion of commuters using private cars dropped sharply from $78 \%$ to $14 \%$, and the number of commuters choosing public transportation and taxi/ carpooling increased. The LPR policy prompted nearly half of the private car drivers surveyed to increase the use of public transportation on working days, with the other half still using private or non-private vehicles.

A stepwise multivariate regression model was adopted to analyze the relationship between influencing factors and post-acceptance. The analysis results show the factors affecting commuters' post-acceptance of LPR policies, i.e., perceived effectiveness, social norms, responsibility attribution, problem perception, and perceived cost-benefit (Table 3 ), where $B$ stands for ordinary coefficients and

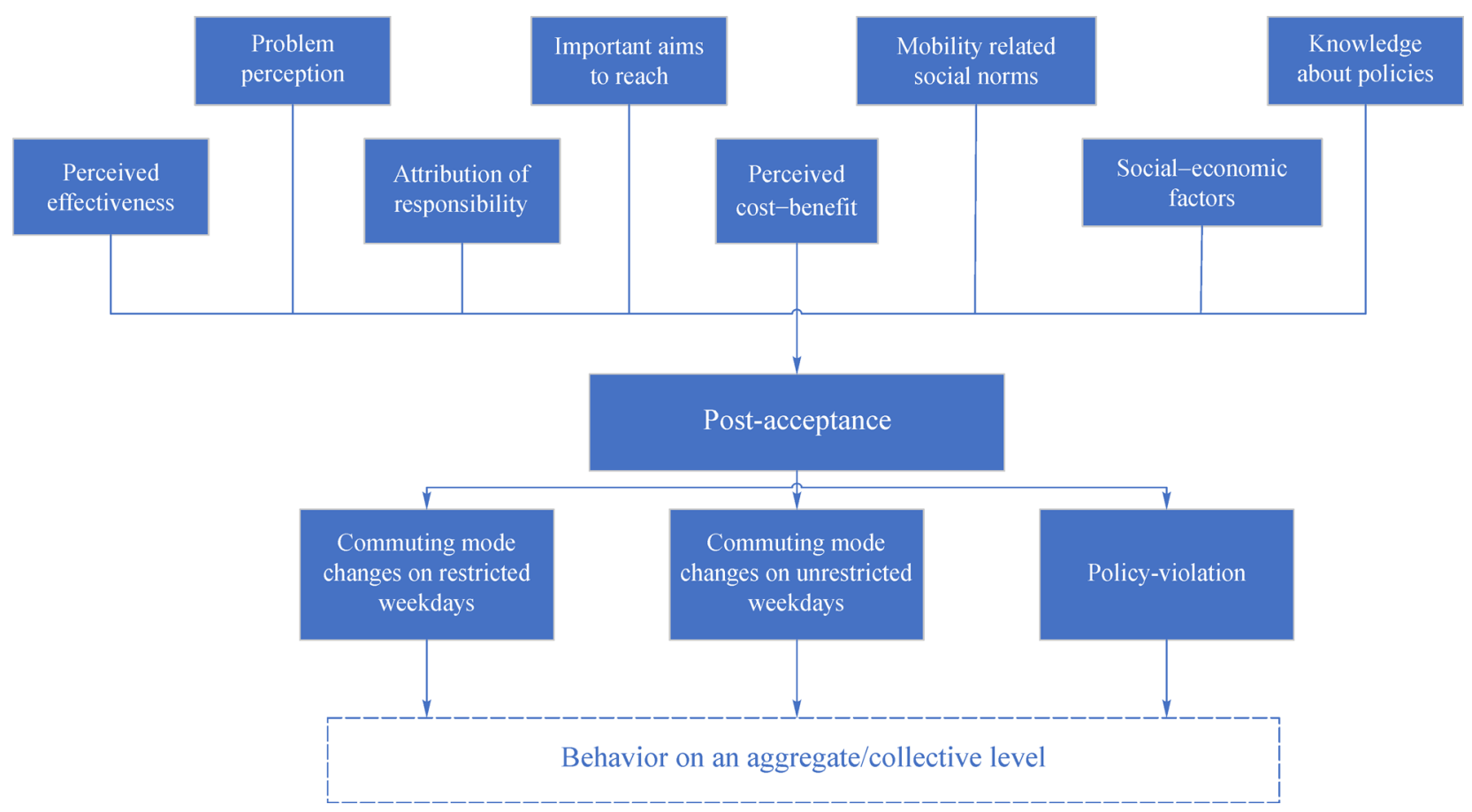

Fig. 6 Theoretical framework of acceptability of and behavior reactions toward LPR policy. 
Table 3 Stepwise multiple regression analysis of post-acceptance (according to Jia et al. (2017))

\begin{tabular}{lccc}
\hline Predictor variables & $B$ & $\beta$ & Sig. \\
\hline Perceived effectiveness & 0.230 & 0.398 & 0 \\
Social norms & 0.166 & 0.270 & 0 \\
Responsibility attribution & 0.075 & 0.120 & 0.013 \\
Problem perception & 0.093 & 0.120 & 0.005 \\
Perceived cost-benefit & 0.118 & 0.119 & 0.011 \\
Constant & -0.870 & & 0 \\
\hline
\end{tabular}

Note: $R^{2}=0.681, p=0$.

$\beta$ is the standard coefficient.

Consistent with previous findings, perceived effectiveness is positively correlated with post-acceptance and is the most important factor. This result indicates that one of the main reasons for the high acceptance of the LPR policy in Tianjin may be its significant effect on alleviating traffic congestion. Social norms are also positively correlated with post-acceptance, thus suggesting that public opinion may be critical to the acceptance of LPR policies. However, contrary to expectations, important aims, knowledge about policies, and socioeconomic factors exert insignificant impact on respondents' acceptance of the LPR policy. The explanation for important aims is that the respondents may lack serious consideration of trafficrelated issues. As for knowledge about policies being insignificant, the interviewees were all car-owning commuters affected by the LPR policy and thus all knew about the policy details. As for the influence of socioeconomic factors, no generally accepted conclusion has been derived so far, indicating that the influence of socioeconomic factors on the acceptance of the LPR policy may be interesting and thus deserves further study.

The study then examined the relationship between postacceptance and noncompliant behaviors. First, commuting mode changes was measured by ranking the travel modes in terms of their contribution to traffic congestion: Private car, taxi/carpool, and public transportation. The results are shown in Table 4. Thereafter, the correlation between the acceptance of the two groups (private car owners and commuters choosing public transit and taxi/carpooling) and the changes in commuting mode was explored

Table 4 Measurements of commuting mode changes (numbers from 1 to 5 indicate worst, worse, unchanged, better, and best, respectively)

\begin{tabular}{lccc}
\hline Before implementation & \multicolumn{3}{c}{ After implementation } \\
\cline { 2 - 4 } & Private car & Taxi/Carpooling & Public transit \\
\hline Private car & 3 & 4 & 5 \\
Taxi/Carpooling & 2 & 3 & 4 \\
Public transit & 1 & 2 & 3 \\
\hline
\end{tabular}

(Table 5). Finally, the correlation between noncompliance and acceptance of the LPR policy was studied. As shown in Table 6, the frequency of noncompliant behaviors is decreased as the commuters' acceptance of the LPR policy increases.

In sum, post-acceptance herein does not merely indicate public support or attitude toward the LPR policy. It is rather considered as a key factor to determine the extent to which the expected goals of the LPR policy can be effectively fulfilled. Specifically, it includes two points:

1) High post-acceptance increases the direct influence of the LPR policy on restricted commuters. When restricted, more drivers will be encouraged by a higher acceptance rate to switch to public transportation while drivers with a lower acceptance rate will still use (private or non-private) cars even though those cars may be restricted. When the level of post-acceptance is higher in general, the number of commuters who do not comply with the policy will decrease.

2) The higher degree of post-acceptance inhibits the negative influence of the LPR policy on unrestricted commuters. As traffic congestion tends to ease off after the implementation of the LPR policy, some commuters who previously did not use private cars may turn to private cars to commute on unrestricted weekdays. However, those who are more receptive are likely to retain their original commuting mode instead of using a private car.

As implied by the results, low acceptance rates may weaken effectiveness because policies may not achieve the desired effects. Combined with the analysis of several factors affecting post-acceptance, the following four management suggestions are proposed for transportation authorities.

1) The LPR policy should be carefully designed in detail; it should cover the number of restricted cars used, penalty rules, restrictions in time/area, and implementation procedure.

2) An individual's social norm and attribution of responsibility cannot be directly changed by administrative orders. Therefore, transportation authorities should take various measures, such as public education and publicity, to provide commuters with appropriate knowledge about the causes and solutions of transportation-related problems.

3) Problem perception is the key to improving the postacceptance of the LPR policy. This finding indicates that only when commuters are aware of the seriousness of traffic-related problems can the policy be implemented.

4) Generally, the LPR policy should be combined with the vehicle ownership control policy. Car ownership control policies can curb the growth of the number of private cars. If these control strategies are not implemented simultaneously, the effectiveness of the LPR strategy may decline rapidly because of the rapid increase in the total number of private cars. 
Table 5 Correlation between post-acceptance and commuting mode changes among private car owners and commuters choosing public transit and taxi/carpooling

\begin{tabular}{|c|c|c|c|c|c|c|}
\hline & \multicolumn{3}{|c|}{ Private car owners } & \multicolumn{3}{|c|}{ Commuters choosing public transit and taxi/carpooling } \\
\hline & $B$ & $\beta$ & Sig. & $B$ & $\beta$ & Sig. \\
\hline \multicolumn{7}{|c|}{ Unrestricted weekdays } \\
\hline Constant & 2.974 & & 0 & 1.946 & & 0 \\
\hline Post-acceptance & 0.023 & 0.088 & 0.093 & 0.152 & 0.195 & 0.046 \\
\hline \multicolumn{7}{|l|}{ Restricted weekdays } \\
\hline Constant & 5186 & & 0 & 5186 & & 0 \\
\hline Post-acceptance & 0.084 & 0.033 & 0.011 & -0.028 & 0.290 & 0.340 \\
\hline
\end{tabular}

Table 6 Correlation between post-acceptance and noncompliant behaviors

\begin{tabular}{lccc}
\hline & $B$ & $\beta$ & Sig. \\
\hline Constant & 3.905 & & 0 \\
Post-acceptance & 0.110 & 0.149 & 0.001 \\
\hline
\end{tabular}

\section{Contributions and limitations}

The sustainable development of urban transportation plays a vital role in the national economy and people's livelihood. Given its unique characteristics, the development of transportation systems is under intense pressure from socioeconomic and environmental systems. On the one hand, the transportation system needs to improve efficiency to meet the daily increasing mobility demand of persons or materials in the socioeconomic system. On the other hand, it should reduce resource consumption and emissions to meet the requirements of an environmentally friendly society. These two seemingly contradictory requirements raise significant challenges to sustainable development-oriented transportation management. The pressure from socioeconomic and environmental systems seems to impose a paradoxical demand on urban transportation systems. Inspired by this issue, this study proposes a solution that is rooted in the origin of all complex transportation activities, that is, individual behavior.

To achieve a sustainable transportation system, this study argues that we must attach importance to the guidance of residents' transportation behaviors from the perspective of "system emergence". In this study, we propose a hierarchical analysis framework, which divides the management of transportation systems into four levels from the macro to the micro levels. From top to bottom of the framework, several issues on different transportationrelated behaviors, including purchasing behaviors toward NEVs, choice behaviors toward green travel mode, and behavioral reactions toward TDM policies, are analyzed. Finally, on the basis of the research results, useful managerial insights are extracted for transportation administrators to guide the design and improvement of sustainable traffic management policies.

Nonetheless, this study has several limitations. As this work mainly focuses on traditional travel modes, it is not comprehensive enough given the lack of attention to and consideration of new travel modes and services, including bicycle sharing and customized buses. Transportation services are also an important factor for the sustainable development of urban transportation systems, which deserve adequate research attention.

Open Access This article is licensed under a Creative Commons Attribution 4.0 International License, which permits use, sharing, adaptation, distribution and reproduction in any medium or format, as long as you give appropriate credit to the original author(s) and the source, provide a link to the Creative Commons licence, and indicate if changes were made.

The images or other third party material in this article are included in the article's Creative Commons licence, unless indicated otherwise in a credit line to the material. If material is not included in the article's Creative Commons licence and your intended use is not permitted by statutory regulation or exceeds the permitted use, you will need to obtain permission directly from the copyright holder. To view a copy of this licence, visit http://creativecommons.org/licenses/by/4.0/.

\section{References}

Bergstad C J, Gamble A, Hagman O, Polk M, Garling T, Olsson L E (2011). Affective-symbolic and instrumental-independence psychological motives mediating effects of socio-demographic variables on daily car use. Journal of Transport Geography, 19(1): 33-38

Biresselioglu M E, Demirbag Kaplan M, Yilmaz B K (2018). Electric mobility in Europe: A comprehensive review of motivators and barriers in decision making processes. Transportation Research Part A: Policy and Practice, 109: 1-13

Bjerkan K Y, Norbech T E, Nordtomme M E (2016). Incentives for promoting Battery Electric Vehicle (BEV) adoption in Norway. Transportation Research Part D: Transport and Environment, 43: 169-180

Bonges III H A, Lusk A C (2016). Addressing electric vehicle (EV) sales and range anxiety through parking layout, policy and regulation. Transportation Research Part A: Policy and Practice, 83: 63-73 Botetzagias I, Dima A, Malesios C (2015). Extending the Theory of 
Planned Behavior in the context of recycling: The role of moral norms and of demographic predictors. Resources, Conservation and Recycling, 95: 58-67

Cantillo V, Amaya J D, Ortúzar J (2010). Thresholds and indifference in stated choice surveys. Transportation Research Part B: Methodological, 44(6): 753-763

Carley S M, Krause R W, Lane B D, Graham J (2013). Intent to purchase a plug-in electric vehicle: A survey of early impressions in large US cites. Transportation Research Part D: Transport and Environment, 18: $39-45$

Chen H, Long R, Niu W, Feng Q, Yang R (2014). How does individual low-carbon consumption behavior occur?-An analysis based on attitude process. Applied Energy, 116: 376-386

Choi H, Jang J, Kandampully J (2015). Application of the extended VBN theory to understand consumers' decisions about green hotels. International Journal of Hospitality Management, 51: 87-95

Chowdhury S, Dey S, Tripathi S, Beig G, Mishra A, Sharma S (2017). "Traffic intervention" policy fails to mitigate air pollution in megacity Delhi. Environmental Science \& Policy, 74: 8-13

Clarka C F, Kotchenb M J, Moorea M R (2003). Internal and external influences on pro-environmental behavior: Participation in a green electricity program. Journal of Environmental Psychology, 23(3): 237-246

Coffman M, Bernstein P, Wee S (2016). Electric vehicles revisited: A review of factors that affect adoption. Transport Reviews, 37(1): 79-93

Cohen M, Lobel R, Perakis G (2016). The impact of demand uncertainty on consumer subsidies for green technology adoption. Management Science, 62(5): 1235-1258

Cristea M, Paran F, Delhomme P (2013). Extending the theory of planned behavior: The role of behavioral options and additional factors in predicting speed behavior. Transportation Research Part F: Psychology and Behaviour, 21: 122-132

Dacko S, Spalteholz C (2014). Upgrading the city: Enabling intermodal travel behaviour. Technological Forecasting and Social Change, 89: $222-235$

de Groot J I M, Steg L (2010). Relationships between value orientations, self-determined motivational types and pro-environmental behavioural intentions. Journal of Environmental Psychology, 30(4): $368-378$

Diamond D (2009). The impact of government incentives for hybridelectric vehicles: Evidence from US states. Energy Policy, 37(3): 972-983

Dittmar H (1992). The Social Psychology of Material Possessions: To Have is To Be. London: Harvester Wheatsheaf

Donald I, Cooper S, Conchie S (2014). An extended theory of planned behaviour model of the psychological factors affecting commuters' transport mode use. Journal of Environmental Psychology, 40: 39-48

Du H, Chen Z, Zhang Z, Southworth F (2020). The rebound effect on energy efficiency improvements in China's transportation sector: A CGE analysis. Journal of Management Science \& Engineering, 5(4): 249-263

Du H, Liu D, Sovacool B K, Wang Y, Ma S, Li R Y M (2018). Who buys New Energy Vehicles in China? Assessing social-psychological predictors of purchasing awareness, intention, and policy. Transportation Research Part F: Psychology and Behaviour, 58: 56-69
Eskeland G S, Feyzioglu T (1997). Rationing can backfire: The "day without a car" in Mexico City. The World Bank Economic Review, 11(3): 383-408

Gadenne D, Sharma B, Kerr D, Smith T (2011). The influence of consumers' environmental beliefs and attitudes on energy saving behaviours. Energy Policy, 39(12): 7684-7694

Gallego F, Montero J, Salas C (2013). The effect of transport policies on car use: A bundling model with applications. Energy Economics, 40 (Supplement 1): S85-S97

Gärling T, Fujii S, Gärling A, Jakobsson C (2003). Moderating effects of social value orientation on determinants of proenvironment. Journal of Environmental Psychology, 23(1): 1-9

Gärling T, Jakobsson C, Loukopoulos P, Fujii S (2008). Acceptability of road pricing. In: Verhoef E, Bliemer M C J, Steg L, van Wee B, eds. Pricing in Road Transport: A Multi-Disciplinary Perspective, Chapter 10. Edward Elgar Publishing

Geng J, Long R, Hong C, Li Q (2018). Urban residents' response to and evaluation of low-carbon travel policies: Evidence from a survey of five eastern cities in China. Journal of Environmental Management, 217: $47-55$

Goddard H C (1997). Optimal restrictions on vehicle use for urban sustainability for Mexico City. International Journal of Environment and Pollution, 7(3): 357-374

Hafner R, Walker I, Verplanken B (2017). Image, not environmentalism: A qualitative exploration of factors influencing vehicle purchasing decisions. Transportation Research Part A: Policy and Practice, 97: $89-105$

Hu X, Moura S, Murgovski N, Egardt B, Cao D (2016). Integrated optimization of battery sizing, charging, and power management in plug-in hybrid electric vehicles. IEEE Transactions on Control Systems Technology, 24(3): 1036-1043

Hu X, Murgovski N, Johannesson L, Egardt B (2015). Optimal dimensioning and power management of a fuel cell/battery hybrid bus via convex programming. IEEE/ASME Transactions on Mechatronics, 20(1): 457-468

Jia N, Li L, Ling S, Ma S, Yao W (2018). Influence of attitudinal and low-carbon factors on behavioral intention of commuting mode choice-A cross-city study in China. Transportation Research Part A: Policy and Practice, 111: 108-118

Jia N, Zhang Y, He Z, Li G (2017). Commuters' acceptance of and behavior reactions to license plate restriction policy: A case study of Tianjin, China. Transportation Research Part D: Transport and Environment, 52(Part B): 428-440

Jiang P, Chen Y, Xu B, Dong W, Kennedy E (2013). Building low carbon communities in China: The role of individual's behaviour change and engagement. Energy Policy, 60: 611-620

Jraiw K (1991). Travel demand management: Options and implementation. The Road to Knowledge. Washington, DC, NW: The National Academies of Sciences, Engineering, and Medicine

Kaiser F, Scheuthle H (2003). Two challenges to a moral extension of the theory of planned behavior: Moral norms and just world beliefs in conservationism. Personality and Individual Differences, 35(5): 1033-1048

Krupa J, Rizzo D M, Eppstein M J, Brad Lanute D, Gaalema D E, Lakkaraju K, Warrender C E (2014). Analysis of a consumer survey on plug-in hybrid electric vehicles. Transportation Research Part A: 
Policy and Practice, 64(2): 14-31

Lane B, Potter S (2007). The adoption of cleaner vehicles in the UK: Exploring the consumer attitude-action gap. Journal of Cleaner Production, 15(11-12): 1085-1092

Li R, Guo M (2016). Effects of odd-even traffic restriction on travel speed and traffic volume: Evidence from Beijing Olympic Games. Journal of Traffic and Transportation Engineering, 3(1): 71-81

Lind H, Nordfjærn T, Jørgensen S, Rundmo T (2015). The value-beliefnorm theory, personal norms and sustainable travel mode choice in urban areas. Journal of Environmental Psychology, 44: 119-125

Ling S, Jia N, Ma S, Lan Y, Hu W (2019). An incentive mechanism design for bus subsidy based on the route service level. Transportation Research Part A: Policy and Practice, 119: 271-283

Liobikienè G, Mandravickaite J, Bernatonienė J (2016). Theory of planned behavior approach to understand the green purchasing behavior in the EU: A cross-cultural study. Ecological Economics, 125: $38-46$

Liu D, Du H, Southworth F, Ma S (2017). The influence of socialpsychological factors on the intention to choose low-carbon travel modes in Tianjin, China. Transportation Research Part A: Policy and Practice, 105: 42-53

Lois D, López-Sáez M (2009). The relationship between instrumental, symbolic and affective factors as predictors of car use: A structural equation modeling approach. Transportation Research Part A: Policy and Practice, 43(9-10): 790-799

Lo S H, van Breukelen G J P, Peters G J Y, Kok G (2016). Commuting travel mode choice among office workers: Comparing an Extended Theory of Planned Behavior model between regions and organizational sectors. Travel Behaviour \& Society, 4: 1-10

Marsden G, Docherty I (2013). Insights on disruptions as opportunities for transport policy change. Transportation Research Part A: Policy and Practice, 51(3): 46-55

Marsden G, Mullen C, Bache I, Bartle I, Flinders M (2014). Carbon reduction and travel behaviour: Discourses, disputes and contradictions in governance. Transport Policy, 35: 71-78

Martinsson J, Lundqvist L, Sundström A (2011). Energy saving in Swedish households. The (relative) importance of environmental attitudes. Energy Policy, 39(9): 5182-5191

Mersky A, Sprei F, Samaras C, Qian Z (2016). Effectiveness of incentives on electric vehicle adoption in Norway. Transportation Research Part D: Transport and Environment, 46: 56-68

Mohan D, Tiwari G, Goel R, Lahkar P (2017). Evaluation of Odd-Even Day traffic restriction experiments in Delhi, India. Journal of the Transportation Research Board, 2627(1): 9-16

Noppers E H, Keizer K, Bolderdijk J W, Steg L (2014). The adoption of sustainable innovations: Driven by symbolic and environmental motives. Global Environmental Change, 25: 52-62
Noppers E H, Keizer K, Bockarjova M, Steg L (2015). The adoption of sustainable innovations: The role of instrumental, environmental, and symbolic attributes for earlier and later adopters. Journal of Environmental Psychology, 44: 74-84

Rezvani Z, Jansson J, Bodin J (2015). Advances in consumer electric vehicle adoption research: A review and research agenda. Transportation Research Part D: Transport and Environment, 34: 122-136

Rienstra S, Rietveld P, Verhoef E (1999). The social support for policy measures in passenger transport: A statistical analysis for the Netherlands. Transportation Research Part D: Transport and Environment, 4(3): 181-200

Schade J, Schlag B (2000). Acceptability of Urban Transport Pricing. Helsinki: VATT Institute for Economic Research

She Z, Sun Q, Ma J, Xie B (2017). What are the barriers to widespread adoption of battery electric vehicles? A survey of public perception in Tianjin, China. Transport Policy, 56: 29-40

Steg L, Gifford R (2005). Sustainable transportation and quality of life. Journal of Transport Geography, 13(1): 59-69

Steg L, Vlek C (2009). Encouraging pro-environmental behaviour: An integrative review and research agenda. Journal of Environmental Psychology, 29(3): 309-317

Steg L, Vlek C, Slotegraaf G (2001). Instrumental-reasoned and symbolic-affective motives for using a motor car. Transportation Research Part F: Psychology and Behaviour, 4(3): 151-169

Van H T, Choocharukul K, Fujii S (2014). The effect of attitudes toward cars and public transportation on behavioral intention in commuting mode choice-A comparison across six Asian countries. Transportation Research Part A: Policy and Practice, 69: 36-44

Viard B, Fu S (2015). The effect of Beijing's driving restrictions on pollution and economic activity. Journal of Public Economics, 125: 98-115

Wang G, Qi H, Xu H, Ryu S (2020). A mixed behaviour equilibrium model with mode choice and its application to the endogenous demand of automated vehicles. Journal of Management Science \& Engineering, 5(4): 227-248

Wang L, Xu J, Qin P (2014). Will a driving restriction policy reduce car trips? - The case study of Beijing, China. Transportation Research Part A: Policy and Practice, 67(1): 279-290

Xu S, Liu T, Jia N, Wang P, Liu P, Ma S (2020). The effects of transportation system improvements on urban performances with heterogeneous residents. Journal of Management Science \& Engineering, 5(4): 287-302

Yang Y, Tian Q, Wang Y (2020). Who is more likely to get a ride and where is easier to be picked up in ride-sharing mode? Journal of Management Science \& Engineering, 5(4): 264-286

Zhang D, Tu Y (2021). Green building, pro-environmental behavior and well-being: Evidence from Singapore. Cities, 108: 102980 